\title{
ANALISIS MINAT DAN PERILAKU PENGGUNAAN APLIKASI SHAREIT DENGAN PENDEKATAN UNIFIED THEORY OF ACCEPTANCE AND USE OF TECHNOLOGY
}

\author{
Qona'ah El Hasan', Budi Permana ${ }^{2}$ \\ Program Pascasarjana Sistem Informasi \\ Sekolah Tinggi Manajemen Informatika dan Komputer LIKMI \\ Bandung, Indonesia \\ qonaah.elz@gmail.com
}

\begin{abstract}
Technology acceptance is important for identifying elements that influence the user, so it is easy to use apps. The evaluation of technology reception will help to improve the system better in the future and indicate whether the system succeeded or not, so the users will keep using the apps. SHAREit is a program that can be downloaded on the Android Smartphone platform and on personal computers. It is able to transfer documents, pictures, music, and videos rapidly. Even so, the applications are faster than Bluetooth and Wifi. Then, Indonesia is the biggest second market for SHAREit in the world. The research is proposed to detect how the user accepts SHAREit in Kuningan Regency by using the Unified Theory of Acceptance and Use of Technology Method. It has been modified. The instrument of research is a questionnaire then distributed to user communities of SHAREit in Kuningan Regency by using Incidental Sampling, instrument testing and data processing Structural Equation Modelling by AMOS apps. Furthermore, the hypothesis is arranged through moderator variables; age, gender, and experience. The result of research indicates that there are three factors possessing positive influence on Behavioral Intention of usage SHAREit, such as Performance Expectancy, Social Influence, and Facilitating Conditions. A factor influencing use of behavioral is behavioral intention. Whereas, Personal Innovativeness in the Domain of Information Technology and Effort Expectancy do not influence the Behavioral Intention of SHAREit Apps in Kuningan Regency.
\end{abstract}

Keywords: AMOS, PIIT, SHAREit Apps, Technology Acceptance, UTAUT

\section{PENDAHULUAN}

Kemajuan teknologi informasi di Indonesia semakin pesat dan mencakup berbagai aspek. Masyarakat dapat menggunakan berbagai aplikasi untuk mempermudah kegiatannya yang bisa dipasang di ponsel pintar. Tak terkecuali layanan untuk transfer file semakin canggih dengan aplikasi pendukung, salah satunya dengan aplikasi SHAREit. SHAREit merupakan aplikasi yang bisa diinstal di platform android dan berguna dalam pemindahan file dokumen, gambar, musik, ataupun video dengan sangat cepat berkat dukungan Wi-Fi. SHAREit diklaim memiliki kecepatan yang lebih baik dibanding Bluetooth maupun Wi-Fi. Aplikasi ini digagas oleh Lenovo namun perangkat berbasis Windows, Windows Phone, iOS, dan Android juga bisa menginstall aplikasi ini. 
Kesuksesan suatu teknologi informasi merupakan harapan dari semua pihak yang terlibat dalam penggunaan dan pembuatannya, diperlukan proses evaluasi untuk agar suatu teknologi ataupun sistem informasi dapat berjalan dengan lebih baik lagi di masa depan dan memiliki keunggulan bersaing. Salah satu cara mengevaluasinya adalah dengan meneliti perilaku pengguna suatu teknologi informasi untuk mengetahui apakah telah sukses atau tidaknya suatu aplikasi.

Tujuan dari penelitian ini adalah untuk mengetahui pengaruh ekspektasi kinerja, ekspektasi usaha, faktor sosial juga pengaruh kemauan seseorang untuk mencoba teknologi informasi baru terhadap niat penggunaan aplikasi SHAREit, selain itu juga untuk mengetahui pengaruh kondisi yang memfasilitasi dan minat penggunaan aplikasi terhadap perilaku penggunaan aplikasi SHAREit.

Dengan meneliti faktor-faktor apa saja yang berpengaruh terhadap minat dan niat penggunaan aplikasi SHAREit, maka pengembang aplikasi dapat menganalisa dan mengembangkan aplikasi dengan lebih baik agar membuat pengguna merasakan kemudahan penggunaan suatu sistem sehingga dapat meningkatkan minat dan niat pengguna dalam menggunakan aplikasi SHAREit. Hal ini juga dapat mencegah pengguna agar tidak berpaling menggunakan aplikasi lain yang sejenis.

Penelitian yang dilakukan oleh Hendro Gunawan dan Benyamin Langgu Sinaga pada tahun 2018 menggunakan variabel tambahan yaitu Personal Innovativeness in the Domain of Information Technology (PIIT) dan juga Anxiety. Variabel moderator yang digunakan difokuskan pada variabel gender. Hasil penelitian ini menunjukkan bahwa Personal Innovativeness in the Domain of Information Technology berpengaruh secara signifikan pada Behavioral Intention. Menurut penelitian Aygul Turan dkk pada tahun 2015 juga disebutkan bahwa Personal Innovativeness merupakan akar dari model UTAUT. Model Unified Theory of Acceptance and Use of Technology merupakan hasil evaluasi delapan model user acceptance terkemuka yang diintegrasikan ke dalam sebuah model baru (Ramon Palau Saumell, 2019). Oleh karena itu peneliti ingin meneliti tentang minat dan perilaku penggunaan aplikasi SHAREit di Kabupaten Kuningan dengan model Unified Theory of Acceptance and Use of Technology (UTAUT) dan tetap menggunakan variable moderator age, gender dan experience dan menambahkan 
variabel Personal Innovativeness in the Domain of Information Technology (PIIT) untuk mengetahui apakah pengaruh kemauan seseorang untuk mencoba teknologi informasi baru terhadap niat penggunaan aplikasi. Variabel tersebut akan dihubungkan dengan Behavioral Intention.

\section{METODOLOGI PENELITIAN}

Penelitian ini menggunakan metode kuantitatif deskriptif, yaitu penelitian yang pada proses penelitiannya menggunakan data-data yang diolah kemudian dianalisis serta ditarik kesimpulannya.

Penelitian dimulai dengan melakukan observasi terhadap masyarakat yang menggunakan aplikasi SHAREit, dilanjutkan dengan mencari literatur terkait materi lainnya yang dibutuhkan dan dilakukan pengembangan dari model UTAUT sesuai kebutuhan. Selanjutnya penentuan variabel laten dan manifest, kemudian disusun hipotesisnya melalui pengumpulan data dilapangan dengan instrumen yang sesuai. Indikator didesain dengan menggunakan skala likert dan dilakukan pembuatan kuesioner berdasarkan indikator yang disesuaikan dengan variablevariabel tersebut. Setelah kuesioner terisi maka dilakukan identifikasi model, analisis data dengan Structural Equation Modelling (SEM) dengan menggunakan software Amos 24, kemudian model diuji kelayakannya, apabila model belum fit masih dilakukan modifikasi model dalam pengolahan datanya, setelah model dikatakan fit dilakukan pengujian hipotesis dan moderasinya serta kemudian dijabarkan pembahasan dan penarikan kesimpulan dari penelitian ini.

\section{Populasi dan Sampel}

Metode pengumpulan sampel yang digunakan dalam penelitian ini adalah menggunakan non-probability sampling secara insidental. Dalam penelitian ini populasinya adalah seluruh pengguna aplikasi SHAREit di Kabupaten Kuningan.

Populasi dalam penelitian ini tidak diketahui, sehingga rumus yang digunakan untuk menghitung jumlah sampel pada penelitian ini menggunakan rule of thumb yang merupakan perbandingan jumlah sampel terhadap jumlah indikator. Jumlah seluruh variabel manifes (indikator) adalah 23. Sedangkan rule of thumb untuk perbandingan jumlah sampel terhadap jumlah indikator adalah $1: 5$ (Solimun, 2002). Jadi jika indikator dalam penelitian ini sebanyak 23, maka 
minimal sampel yang dibutuhkan adalah 115. Menurut Hair, dkk (1998) juga merekomendasikan jumlah sampel ideal untuk SEM adalah 100 - 400.

Berdasarkan hasil perhitungan diatas maka jumlah sampel minimal yang ditetapkan dalam penelitian ini adalah 115 orang. Dikarenakan data dalam penelitian ini akan diolah menggunakan software AMOS, maka kuesioner akan disebarkan kepada sampel sebanyak 200 orang. Oleh karena itu penelitian ini mendukung dilakukannya pengolahan data dengan SEM.

\section{Variabel dan Indikator dalam Model UTAUT}

Model UTAUT pertama kali dikembangkan oleh Venkatesh. Model ini mengemukakan bahwa ada seperangkat faktor yang mempengaruhi niat penerimaan pengguna secara individu. Pada model UTAUT yang dimodifikasi oleh penulis ini terdapat variabel independen (variabel eksogen) yaitu performance expectancy, effort expectancy, social influence, dan facilitating condition. Dalam penelitian ini ditambahkan juga satu variabel eksogen yaitu Personal Innovativeness in the Domain of Information Technology (PIIT) yang berhubungan langsung dengan behavioral intention, juga variabel moderator yang memperkuat variabel eksogen tersebut, diantaranya adalah age, gender dan experience.

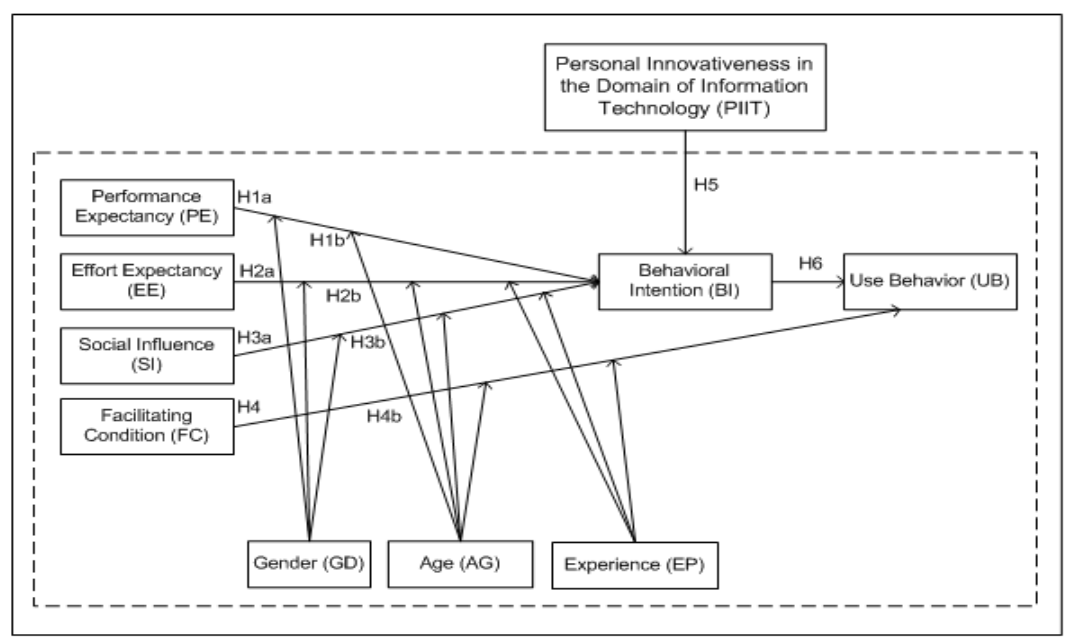

Gambar 1 Model modifikasi UTAUT dalam penelitian

Model UTAUT memiliki variabel dependen dan independen yang diperkuat oleh variabel-variabel moderat. Setiap variabel dependen dan independen memiliki indikator-indikator didalamnya yang digunakan untuk menyusun pernyataanpernyataan. Indikator tersebut digunakan untuk menjelaskan keadaan secara 
keseluruhan variabel tersebut dan harus bermanfaat untuk kepentingan pengambilan keputusan. Penyusunan variabel, indikator \& pernyataan disusun berdasarkan penelitian Venkatesh et al yang dimofifikasi sesuai dengan kebutuhan penelitian.

\section{Hipotesis}

Hipotesis adalah jawaban sementara terhadap rumusan masalah penelitian. Dikatakan sementara karena jawaban yang diberikan baru didasarkan pada teori dan belum menggunakan fakta. Dari hipotesis tersebut akan dilakukan penelitian lebih lanjut untuk membuktikan apakah hipotesis tersebut benar adanya atau tidak benar. Hipotesis yang akan diuji dalam penelitian ini ditunjukkan pada tabel dibawah ini:

Tabel 1. Hipotesis

\begin{tabular}{ll}
\hline HIPOTESIS \\
\hline H1 & $\begin{array}{l}\text { Ekspektasi kinerja (PE) berpengaruh terhadap niat menggunakan(BI) } \\
\text { aplikasi SHAREit }\end{array}$ \\
H2 & $\begin{array}{l}\text { Ekspektasi usaha (EE) berpengaruh terhadap niat menggunakan(BI) } \\
\text { aplikasi SHAREit }\end{array}$ \\
H3 & $\begin{array}{l}\text { Faktor sosial (SI) berpengaruh terhadap niat menggunakan(BI) aplikasi } \\
\text { SHAREit } \\
\text { Kondisi yang memfasilitasi (FC) berpengaruh terhadap perilaku } \\
\text { menggunakan(UB) aplikasi SHAREit }\end{array}$ \\
H5 & $\begin{array}{l}\text { Kemauan seseorang untuk mencoba teknologi informasi baru (PIT) } \\
\text { berpengaruh terhadap niat menggunakan(BI) aplikasi SHAREit } \\
\text { Minat penggunaan (BI) berpengaruh terhadap perilaku } \\
\text { menggunakan(UB) aplikasi SHAREit }\end{array}$ \\
H6
\end{tabular}

\section{Uji Instrumen Penelitian}

Uji kualitas instrumen dilakukan untuk mengetahui apakah instrumen penelitian sudah memenuhi kriteria valid dan reliabel. Dalam penelitian ini terdiri dari 23 pernyataan yang mewakili indikator dengan menggunakan aplikasi AMOS versi 22. Hasil yang diperoleh dari pengujian kualitas instrumen dengan uji validitas dan reliabilitas CFA dengan AMOS versi 22 dapat dilihat pada tabel berikut.

Tabel 2. Hasil Uji Validitas \& Reliabilitas Instrumen

\begin{tabular}{lllll}
\hline Variabel & Butir & Factor Loading & $\begin{array}{l}\text { Construct } \\
\text { Reliability }\end{array}$ & $\begin{array}{l}\text { Variance } \\
\text { Extracted }\end{array}$ \\
\hline PE & PE1 & 0,917 & & \\
& PE2 & 0,895 & 0,9286 & 0,7651 \\
& PE3 & 0,859 & & \\
& PE4 & 0,825 & & 0,8060 \\
\hline EE & EE1 & 0,926 & 0,9256 & 0,860 \\
\hline
\end{tabular}




\begin{tabular}{lllll}
\hline Variabel & Butir & Factor Loading & $\begin{array}{l}\text { Construct } \\
\text { Reliability }\end{array}$ & $\begin{array}{l}\text { Variance } \\
\text { Extracted }\end{array}$ \\
\hline \multirow{2}{*}{ SI } & EE2 & 0,858 & & \\
& EE3 & 0,908 & & \\
& SI1 & 0,853 & 0,8829 & 0,7159 \\
\hline PIIT & SI2 & 0,797 & & \\
& SI3 & 0,886 & 0,8938 & 0,7377 \\
& PIT1 & 0,894 & & \\
\hline BI & PIIT2 & 0,803 & & \\
& PIT3 & 0,877 & 0,9445 & \\
& BI1 & 0,946 & & \\
& BI2 & 0,956 & & \\
FC & BI3 & 0,862 & 0,7186 \\
& FC1 & 0,851 & & \\
& FC2 & 0,805 & & \\
& FC3 & 0,883 & & \\
\hline UB & FC4 & 0,850 & 0,9107 & \\
& UB1 & 0,935 & & \\
& UB2 & 0,915 & &
\end{tabular}

Sumber: Data Primer Diolah, 2020

Untuk uji validitas data formal yang menggunakan AMOS versi 22 dari seluruh daftar pertanyaan yang mewakili setiap variabel yang diujikan. Menurut Ghozali (2011), data dikatakan valid apabila nilai factor loading $>0,5$. Hasil uji validitas menunjukkan bahwa seluruh indikator pertanyaan yang mewakili 7 variabel dinyatakan valid dengan nilai $>0,5$.

Ghozali (2011) menyatakan bahwa hasil pengujian dikatakan reliabel jika memiliki nilai construct reliability $>0,7$ dan nilai average variance extracted $>0,5$. Hasil pengujian ini menunjukkan bahwa nilai $C . R$ pada masing-masing variabel lebih besar dari 0,7 dan nilai $A V E$ pada masing-masing variabel lebih besar dari 0,5. Berdasarkan hasil tersebut maka dapat disimpulkan bahwa keseluruhan instrumen penelitian tersebut reliable sehingga dapat digunakan dalam penelitian ini.

\section{HASIL DAN PEMBAHASAN}

\section{Karakteristik Responden}

Kuesioner yang telah disebar kepada 200 responden yang merupakan masyarakat pengguna aplikasi SHAREit di kabupaten Kuningan, namun data kuesioner yang diisi adalah 194 sehingga kuesioner yang bisa yang digunakan dalam penelitian ini berjumlah 194 orang. 
Angket disebarkan melalui google form. Berdasarkan jenis kelamin, responden pada penelitian ini terdiri dari $47,9 \%$ perempuan dan $52,1 \%$ orang lakilaki. Menurut usia responden penelitian dikategorikan dalam tiga kategori, yaitu rentang usia 12-25 tahun sebanyak 37,6\%, usia 26-45 tahun sebanyak 38,7\% dan sisanya rentang usia 46-65 tahun sebanyak 23,7\%. Pengalaman (experience) diukur berdasarkan pernah tidaknya responden menggunakan aplikasi lain yang serupa dengan SHAREit. Diketahui bahwa 61,2\% responden pernah menggunakan aplikasi serupa, sedangkan lainnya $38,8 \%$ belum pernah.

\section{Uji Kelayakan Model}

Uji kelayakan model SEM dilakukan melalui measurement model dan structural model. Input matriks yang digunakan adalah kovarian dan korelasi. Estimasi model yang digunakan adalah estimasi maksimum likelihood (ML) estimasi ML telah dipenuhi dengan asumsi sebagai berikut:

\section{a. Uji Normalitas Data}

Uji Normalitas dilakukan dengan menggunkan $\mathrm{z}$ value (critical ratio atau C.R pada output AMOS 22.0) dari nilai skewness dan kurtosis sebaran data. Nilai kritis sebesar $\pm 2,58$ pada tingkat signifikan 0,01 (Ghozali, 2011). Berdasarkan hasil uji normalitas secara univariate mayoritas berdistribusi normal karena nilai critical ratio (c.r) untuk kurtosis (keruncingan) maupun skewness (kemencengan), berada dalam rentang $-2,58$ sampai $+2,58$.

\section{b. Uji Outliers}

Evaluasi terhadap multivariate outliers dapat dilihat melalui output AMOS Mahalanobis Distance. Kriteria yang digunakan pada tingkat $\mathrm{p}<0.001$. Jarak tersebut dievaluasi menggunakan $\mathrm{X}^{2}$ pada derajat bebas sebesar jumlah variabel terukur yang digunakan dalam penelitian. Dalam kasus ini variabelnya adalah 23, kemudian melalui program excel pada fungsi CHIINV masukkan probabilitas dan jumlah variabel terukur, Hasilnya adalah 49,728 . Artinya semua data/kasus yang lebih besar dari 49,728 merupakan outliers multivariate.

Dari hasil pengolahan data didapat nilai dari Mahalonobis Distance dan terdeteksi adanya nilai yang lebih besar dari 49,728, yaitu responden nomor 136, $161,88,6,21,164,79,58,134,142,119,173,172,160,133,85$ dan di drop dari 
penelitian, sehingga total data responden yang digunakan dalam analisis data pada penelitian ini adalah 194 dikurangi 16 responden, yaitu sebanyak 178 responden.

\section{c. Ukuran Sampel}

Penelitian ini menggunakan sampel sebanyak 194 responden, yang setelah dikurangi dari uji outlier menjadi 178 responden yang akan diolah datanya. Mengacu pada pendapat bahwa jumlah sampel yang representative adalah sekitar 100-200 (Imam Ghozali, 2011). Maka, ukuran sampel yang digunakan dalam penelitian ini telah memenuhi asumsi yang di perlukan uji SEM.

\section{d. Menilai Kriteria Goodness of Fit}

Menilai goodness of fit dilakukan untuk mengetahui seberapa fit sebuah model atau cocok dengan sampel data. Setelah melalui langkah-langkah uji asumsi SEM, dihasilkan output path diagram.

Dari output path diagram tahap awal diketahui bahwa nilai TLI ,Comparative Fit Index (CFI), Probability, CMIN/DF , Ajusted GFI (AGFI) dan Root Mean Square Error of Approximation (RMSEA) masih kurang dari dari ambang batas nilai goodness of fit yang telah ditentukan, maka model ini dikatakan belum fit, oleh karena itu dilakukan modifikasi model.

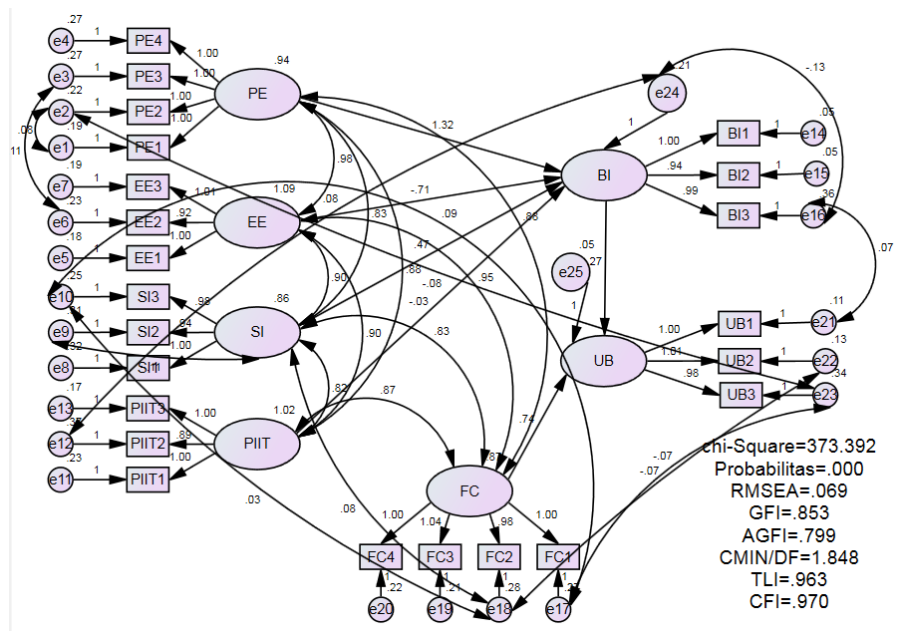

Gambar 2 Output Path Diagram akhir

Pada modifikasi model yang terakhir dalam Modification Indices output AMOS dipilih nilai MI terbesar antara lain kovarian e18 dengan SI sebesar 11.118, e18 dengan e22 sebesar 12.176, e10 dengan e18 sebesar 11.178, e17 dengan E23 
sebesar 9.392, e9 dengan SI sebesar 9.090 sehingga pada model ditambahkan penghubung antar hingga didapatkan model akhir seperti berikut.

Tabel 3. Nilai Goodness of Fit

\begin{tabular}{lccl}
\hline Goodness of fit index & Cut-off value & $\begin{array}{c}\text { Nilai dalam } \\
\text { Model Akhir }\end{array}$ & Model \\
\hline Significant probability & $\geq 0.05$ & 0,000 & Marginal Fit \\
RMSEA & $\leq 0.08$ & 0,069 & Fit \\
GFI & $\geq 0.90$ & 0,853 & Marginal Fit \\
AGFI & $\geq 0.90$ & 0,799 & Marginal Fit \\
CMIN/DF & $\leq 2.0$ & 1,848 & Fit \\
TLI & $\geq 0.90$ & 0,963 & Fit \\
CFI & $\geq 0.90$ & 0,970 & Fit \\
\hline
\end{tabular}

Dari uji model dengan kriteria Goodness of Fit (GFI) tersebut dapat diketahui bahwa nilai TLI, CFI, ditambah CMIN/DF sudah fit, nilai Root Mean Square Error of Approximation (RMSEA) pun sudah fit, chi square sudah mengecil sebesar 373,292 dan kriteria yang lainnya Marginal Fit atau mendekati ambang batas Cut-off Value. Dari beberapa uji kelayakan model, model dikatakan layak jika paling tidak salah satu metode uji kelayakan model terpenuhi (Hair et al, 1998). Oleh karena itu akan dilakukan uji hipotesis.

\section{Uji Hipotesis dan Pembahasan}

Dari analisis calculate estimate pada AMOS didapatkan tabel Regression Weight. Tabel tersebut dapat digunakan untuk melihat Hipotesis yang diajukan apakah diterima atau ditolak.

\section{Uji Hipotesis}

Uji Hipotesis dilakukan dengan menganalisis output yang ada pada Regression Weight, dilihat melalui nilai C.R. dan P.

Tabel 4. Regression Weight Uji Hipotesis

\begin{tabular}{|c|c|c|c|c|c|c|c|}
\hline & & & Estimate & S.E. & C.R. & $\mathrm{P}$ & Label \\
\hline BI & $<--$ & PE & 1.321 & .540 & 2.444 & .015 & par_17 \\
\hline BI & $<--$ & $\mathrm{EE}$ & -.714 & .440 & -1.623 & .105 & par_18 \\
\hline BI & $<--$ & SI & .465 & .140 & 3.327 & $* * *$ & par_19 \\
\hline BI & $<--$ & PIIT & -.034 & .163 & -.208 & .835 & par_21 \\
\hline UB & $<--$ & $\mathrm{FC}$ & .739 & .072 & 10.210 & $* * *$ & par_20 \\
\hline UB & $<--$ & BI & .271 & .058 & 4.679 & $* * *$ & par_22 \\
\hline
\end{tabular}


Pengujian hipotesis dapat dilakukan dengan melihat signifikansi nilai probabilitas sebagai dasar menerima atau menolak hipotesis . Nilai signifikansi yang digunakan yaitu 5\% atau $P<0,05$ serta nilai $c . r>1,96$ (Latan,2013:208).

\section{Pembahasan Hipotesis}

Berdasarkan pemaparan tersebut maka dalam penelitian ini terdapat empat buah hipotesis diterima dan dua buah hipotesis ditolak. Dua buah faktor yang tidak berpengaruh adalah Variabel Effort Expectancy tidak berpengaruh kepada Behavioral intention dan PIIT tidak berpengaruh terhadap niat menggunakan (BI) aplikasi SHAREit di kabupaten Kuningan.

Variabel Effort Expectancy yang tidak berpengaruh kepada Behavioral intention menunjukkan bahwa Ekspektasi usaha atau hasil yang didapat dengan menggunakan aplikasi SHAREit ini tidak akan mempengaruhi minat penguna aplikasi SHAREit untuk berencana terus menggunakan aplikasi ataupun merekomendasikan aplikasi SHAREit ke orang lain. Hal ini sejalan dengan penelitian yang dilakukan oleh tersebut bisa disebabkan karena pengguna SHAREit hanya pada saat mereka butuh alat untuk berbagi file. Variabel PIIT juga tidak berpengaruh terhadap niat menggunakan (BI) aplikasi SHAREit. Hal ini menunjukkan bahwa Kemauan seseorang untuk mencoba teknologi informasi baru tidak memberikan pengaruh yang signifikan kepada minat menggunakan SHAREit, karena kebanyakan pengguna menggunakan aplikasi SHAREit ini bukan karena tingkat keinovatifan personalnya yang tingggi untuk mencoba teknologi informasi baru, melainkan niat mereka untuk menggunakan aplikasi SHAREit dipengaruhi oleh faktor eksternal dari orang lain.

Terdapat empat faktor yang mempunyai pengaruh terhadap minat menggunakan sistem yaitu Variabel Pengaruh Sosial (Social Influence), Ekspektasi usaha (EE) berpengaruh terhadap niat menggunakan (BI) aplikasi SHAREit. Sedangkan Behavioral intention (Minat menggunakan sistem) dan kondisi-kondisi yang memfasilitasi (Facilitating Conditions) memiliki pengaruh positif terhadap Use Behavior (Perilaku Penggunaan) aplikasi SHAREit di kabupaten Kuningan.

Variabel Social Influence berpengaruh secara signifikan pada Behavioral intention, artinya orang-orang disekitar pengguna berpengaruh besar kepada minat 
penggunaan aplikasi SHAREit. Pengguna merasa mereka harus mempunyai aplikasi SHAREit jika akan berbagi file dengan rekan-rekan dilingkungan mereka yang mempunyai aplikasi SHAREit dan jika ada kesulitan maka rekan-rekan tersebut dapat membantu mereka untuk menggunakan aplikasi ini.

Ekspektasi kinerja (PE) berpengaruh terhadap niat menggunakan(BI) aplikasi SHAREit juga berpengaruh secara signifikan pada minat menggunakan SHAREit. Hal ini menunjukkan bahwa Ekspektasi kinerja sangat berpengaruh pada minat pengguna untuk menggunakan aplikasi SHAREit, karena pengguna merasa bahwa aplikasi SHAREit ini dapat mempercepat keperluan mereka dalam berbagi file sehingga apabila ada aplikasi yang dapat mempermudah pekerjaan mereka maka mereka akan sangat berminat menggunakan aplikasi tersebut.

Facilitating Conditions memiliki pengaruh yang signifikan terhadap Use Behavior (Perilaku Penggunaan). Hal ini menunjukkan bahwa kondisi fasilitas yang dimiliki SHAREit merupakan salah satu faktor penting yang diperhatikan oleh pengguna aplikasi. Jika pengguna memiliki perangkat yang mendukung aplikasi SHAREit, adanya fitur-fitur kemudahan dalam aplikasi ini akan berpengaruh pada perilaku pengguna yang akan berulangkali menggunakan aplikasi ini.

Hipotesis terakhir bahwa minat pengguna (Behavior Intention) berpengaruh secara signifikan terhadap perilaku penggunaan aplikasi SHAREit menunjukkan bahwa pengguna yang telah memiliki minat untuk menggunakan aplikasi SHAREit akan menggunakan aplikasi tersebut setiap kali dibutuhkan dan tidak akan mudah berpaling kepada aplikasi lain yang sejenis.

\section{Uji Moderasi Variabel}

Dalam model ini terdapat tiga buah variable moderator yaitu Age (umur), Gender (jenis kelamin) dan experience (pengalaman). Karena itu akan diperlihatkan bagaimana ketiga variable moderator tersebut memoderasi hipotesis yang ada.

\section{Moderasi Variabel Age (Umur)}

Rentang umur dalam penelitian ini dibagi dalam tiga bagian, Analisis berdasarkan umur responden berusia 12-25 tahun, 26-45 tahun dan 46-65 tahun. Berdasarkan pengolahan data dari variabel moderasi umur dapat dilihat bahwa terdapat perbedaan hasil antara pengaruh Performance Expectancy terhadap 
Behavioral Intention, pengaruh Sosial Influence terhadap Behavioral intention, dan pengaruh Personal Innovativeness in the Domain of Information Technology (PIIT) terhadap Behavioral intention.

\section{Moderasi Variabel Gender (Jenis kelamin)}

Berdasarkan jenis kelamin, data bagi responden perempuan dan laki-laki Berdasarkan pengolahan data dari variabel moderasi gender dapat dilihat bahwa terdapat perbedaan hasil antara pengaruh Performance Expectancy terhadap Behavioral Intention dan pengaruh Sosial Influence terhadap Behavioral intention.

\section{Moderasi Variabel Experience (Pengalaman)}

Berdasarkan pengalaman, data bagi responden yang telah berpengalaman menggunakan aplikasi transfer file lainnya saat diolah, disimpulkan bahwa terdapat perbedaan hasil antara pengaruh Performance Expectancy terhadap Behavioral Intention sedangkan pengaruh yang lainnya tidak.

\section{KESIMPULAN}

Berdasarkan penelitian yang telah dilakukan maka dapat diambil kesimpulan bahwa faktor-faktor yang berpengaruh dalam Minat penggunaan (Behavioral intention) aplikasi SHAREit di Kabupaten Kuningan adalah Performance Expectancy, Social Influence, dan Facilitating Conditions. Faktor yang berpengaruh secara positif terhadap Perilaku Penggunaan (Use Behavior) aplikasi SHAREit di Kabupaten Kuningan adalah adalah Behavioral Intention. Sedangkan Personal Innovativeness in the Domain of Information Technology dan Effort Expectancy tidak memiliki pengaruh kepada minat pengunaan.

Dari pengolahan data moderasi, diketahui bahwa Age (umur) dapat memoderasi hubungan kausal antara Performance Expectancy terhadap Behavioral Intention, Sosial Influence terhadap Behavioral intention, dan Personal Innovativeness in the Domain of Information Technology (PIIT) terhadap Behavioral intention. Sedangkan pengaruh lainnya tidak termoderasi oleh umur. Moderasi jenis kelamin menunjukkan bahwa gender dapat memoderasi hubungan kausal antara Performance Expectancy terhadap Behavioral Intention dan Sosial Influence terhadap Behavioral intention. Sedangkan pengaruh lainnya tidak termoderasi oleh gender. Selanjutnya Experience (pengalaman) hanya dapat memoderasi hubungan 
kausal antara Performance Expectancy terhadap Behavioral Intention, sedangkan pengaruh lainnya tidak termoderasi oleh pengalaman.

\section{DAFTAR PUSTAKA}

Aboobucker, I. \&. (2018). What obstruct customer acceptance of internet banking? Security And Privacy Risk, Trust and Website Usability and the Role of Moderators. The Journal of High Technology Management Research.

Agarwal, R. \&. (1998). A conceptual and operational definition of personal innovativeness in the domain of information technology. Information Systems Research.

Aygul Turan, A. O. (2015). A Theoretical Model Proposal: Personal Innovativeness and User Involvement as Antecedents of Unified Theory of Acceptance and Use of Technology. 4th International Conference on Leadership, Technology, Innovation and Business Management (hal. 210:43-51). Elsevier Ltd.

Ghozali, I. (2011). Aplikasi Analisis Multivariate Dengan Program SPSS. Semarang: Badan Penerbit Universitas Diponegoro.

Gunawan, H. a. (2018). Analisis Pengaruh Gender Dalam Penerimaan Teknologi "Smart City" Dengan Model Unified Theory of Acceptance and Use of Technology (UTAUT). SEMNASRISTEK.

Hair, e. a. (1998). Multivariate Data Analysis, Fifth Edition, Prentice Hall, Upper Saddle. New Jersey: River.

Handayani Trie, S. (2015). Analisis Penerapan Model UTAUT (Unified Theory Of Acceptance And Use Of Technology) Terhadap Perilaku Pengguna Sistem Informasi. Fakultas Teknik Elektro, Sekolah Tinggi Teknologi Nasional.

Kusumawardani Winda, E. D. (2018). Analisis Penerimaan dan Penggunaan Aplikasi Work Order Android Menggunakan Metode UTAUT Pada PDAM Kota Malang. Journal Of Computer and Information Technology. 
Latan, H. d. (2013). Analisis Multivariate Teknik dan Aplikasi Menggunakan Program IBM SPSS 20,0. Bandung: Alfabeta.

Nazir, M. (1998). Metode Penelitian. Jakarta: Ghalia Indonesia.

Putri, L. F. (2017). Analisa Faktor-Faktor Yang Mempengaruhi Penerimaan Dan Penggunaan Aplikasi Go-Jek Menggunakan Unified Theory of Acceptance and Use of Technology ( Utaut ). Jurnal Pilar Nusa Mandiri.

Ramon Palau Saumell, S. F. (2019). User Acceptance of Mobile Apps For Restaurants: An Expanded and Extended UTAUT-2. Spain: MDPI.

Reid, M. d. (2008). Integrating Trust and Computer Self Efficiacy with TAM: An Empirical Assesment of Customers Acceptance of Banking Information Systems (BIS) in Jamaica. Journal of Internet Banking and Commerce.

Rosen A.P. (2005). The Effect of Personal Innovativeness on Techmology Acceptance and Use. Oklahoma: Oklahoma State University.

Solimun. (2002). Multivariate Analysis Structural Equation Modelling (SEM) Lisrel dan Amos. Malang.

Sugiyono. (2016). Metode Penelitian Kuantitatif, Kualitatif dan R\&D. Bandung: PT Alfabet.

Venkatesh et al. (2003). User Acceptance of Information Technology : Toward a Unified View. MIS Quarterly.

Venkatesh, V. T. (2012). Consumer Acceptance and Use of Information Technology: Extending the Unified Theory of Acceptance and Use of Tehcnology. MIS Quarterly.

Waluyo, M. (2016). Mudah Cepat Tepat Penggunaan Tools Amos dalam Aplikasi (SEM). Surabaya: UPN Veteran Jatim.

Winduwiratsoko, H. S. (2018). Analisis Penerapan Model Unified Theory Of Acceptance And Use Of Technology (Utaut) Untuk Memahami Penerimaan Dan Penggunaan Layanan E- Banking Oleh Nasabah Di Provinsi Daerah Istimewa Yogyakarta.eprints@UNY. 
NESABAMEDIA.(2020).Retrieved Agustus 14, 2020, from https://www.nesabamedia.com/pengertian-SHAREit/

SHAREit. (2020). Dipetik April 12, 2020, dari SHAREit: https://www.ushareit.com/ 